\title{
Effects of Conjugated Linoleic Acid Isomers on Lipid Metabolism and Gluconeogenesis in Monolayer Cultures of Bovine Hepatocytes
}

\author{
D. G. Mashek and R. R. Grummer ${ }^{1}$ \\ Department of Dairy Science, University of Wisconsin, Madison 53706
}

\section{ABSTRACT}

The objective was to determine the effects of linoleic acid and different isomers of conjugated linoleic acid (CLA) at different concentrations on hepatic lipid and glucose metabolism in the bovine. Monolayer cultures of hepatocytes obtained from 7- to 10-d-old Holstein bull calves were exposed to treatments from 16 to $64 \mathrm{~h}$ after plating. The treatments included $1.0 \mathrm{~m} M$ palmitic acid plus either 0.1 or $1.0 \mathrm{mM}$ of cis-9, cis-12 linoleic acid, cis-9, trans-11 CLA, or trans-10, cis-12 CLA. Metabolism of palmitic acid to cellular triacylglycerol (TAG) was decreased when media contained cis-9, trans-11 compared with trans-10, cis-12 CLA. Total cellular TAG content was increased for the CLA isomers compared to cis-9, cis-12 linoleic acid. Both CLA isomers increased palmitic acid incorporation into phospholipids, cholesterol, and media triacylglycerol compared with cis-9, cis-12 linoleic acid at a concentration of 1.0 $\mathrm{m} M$. Increasing the concentration of treatment fatty acids from 0.1 to $1.0 \mathrm{~m} M$ decreased oxidation of palmitic acid to acid-soluble products, but no effects of fatty acids were observed. There was no treatment effect on rates of gluconeogenesis from propionic acid. Overall, CLA isomers elicited changes in palmitic acid metabolism to cellular and media triacylglycerol, and cellular phospholipids and cholesterol, but had little or no effect on other measured pathways of lipid metabolism or gluconeogenesis in bovine hepatocytes.

(Key words: conjugated linoleic acid, hepatic metabolism, monolayer culture)

Abbreviation key: ASP = acid-soluble products, CLA = conjugated linoleic acid, LA = linoleic acid, TAG = triacylglycerol.

Received April 28, 2003.

Accepted August 28, 2003.

Corresponding author: R. R. Grummer; e-mail: rgrummer@wisc. edu.

${ }^{1}$ Partially funded by: Bioproducts Inc., Church and Dwight, Diamond V, Degussa, Kemin Industries, Land O'Lakes/Farmland Feed, Archer Daniels Midland, Pioneer Hybrids, and Zinpro.

\section{INTRODUCTION}

Since its discovery to possess anticarcinogenic properties, conjugated linoleic acid (CLA) has received extensive research interest. Of the CLA isomers, cis-9, trans-11, and trans-10, cis-12 CLA have received the most attention because of their physiological effects. The primary source of trans-10, cis-12 CLA is from ruminal biohydrogenation of polyunsaturated fatty acids, whereas cis-9, trans-11 CLA is produced from ruminal biohydrogenation and from endogenous desaturation of trans-11 vaccenic acid in adipose and mammary tissue of ruminants (Piperova et al., 2002). The isomers of CLA, especially trans-10, cis-12, are potent inhibitors of enzymes involved in lipid metabolism and thereby affect bovine milk fat composition and concentrations (for a review, see Bauman and Griinari, 2001). For example, CLA decreased $\Delta^{9}$-desaturase activity (Griinari et al., 2000) and acetyl-CoA carboyxlase and fatty acid synthase mRNA abundance in mammary tissue from ruminants (Piperova et al., 2000), thereby decreasing the amount of short- and medium-chain fatty acids in milk fat.

In addition to the mammary gland, CLA has been shown to regulate lipid and energy metabolism in other tissues. Park et al. (1997) showed that CLA could modulate energy partitioning and body composition in rodents. Specifically, cis-9, trans-11, and trans-10, cis-12 CLA isomers stimulate adipose tissue lipolysis, oxidation in adipose and muscle tissue, and decrease lipogenesis in adipose tissue and body fat content (Park et al., 1997; Stangl, 2000). Feeding CLA to rodents or exposing human hepatocyte cell lines to CLA increases $\beta$-oxidation (Belury et al., 1997; Sakono et al., 1999). The effects of CLA on neutral lipid metabolism in the liver are less clear. Hepatic triacylglycerol (TAG) synthesis increased in some studies utilizing HepG2 cells (Igarashi and Miyazawa, 2001) and decreased in others studies of HepG2 cells (Lin et al., 2001) or rats (Rahman et al., 2002) in response to CLA. The effects of CLA on hepatic energy metabolism in the bovine have not been elucidated. Because CLA is an important regulator of energy metabolism and is primarily synthesized in ruminants, we investigated the effects of different concentrations 
of CLA isomers on hepatic lipid and glucose metabolism in the bovine.

\section{MATERIALS AND METHODS}

\section{Reagents}

Sodium thiopental was purchased from Abbott Laboratories (North Chicago, IL), Beuthanasia-D Special from Schering-Plough (Union, NJ), and $\left[1-{ }^{14} \mathrm{C}\right]$ palmitic acid $(50$ to $60 \mathrm{mCi} / \mathrm{mmol})$ and $\left[2-{ }^{14} \mathrm{C}\right]$ propionic acid $(40$ to $60 \mathrm{mCi} / \mathrm{mmol}$ ) from American Radiolabeled Chemicals, Inc. (St. Louis, MO). Type IV collagenase and sodium salts of palmitic and linoleic acids were purchased from Sigma Chemical (St. Louis, MO), cis-9, trans-11 and trans-10, cis-12 CLA from Natural Lipids Ltd. (Hovdebygda, Norway) and BSA from Intergen (Purchase, NY). All other chemicals were of cell culture grade and the highest available purity from Sigma Chemical. Perfusion and wash media were prepared as previously described (Donkin and Armentano, 1993). Incubation media was Dulbecco's modified Eagle's medium (Sigma Chemical) containing $5.5 \mathrm{~m} M$ glucose, 10 $\mathrm{m} M$ HEPES, $4 \mathrm{~m} M$ L-glutamine, $1 \mathrm{~m} M$ pyruvate, and $25 \mathrm{~m} M \mathrm{NaHCO}_{3}$.

\section{Hepatocytes and Treatments}

Three 7- to 10-d-old Holstein bull calves were anesthetized with $1.5 \mathrm{~g}$ of sodium thiopental, the caudate process of the liver was removed, and hepatocytes were isolated as described previously (Donkin and Armentano, 1993). After removal of the caudate process, calves were euthanized with $10 \mathrm{~mL}$ of of Beuthanasia-D Special. Approximately $1.0 \times 10^{6}$ cells were seeded onto 35$\mathrm{mm}$ Falcon Primaria culture dishes (Becton Dickinson, Lincoln Park, NJ) with $1.5 \mathrm{~mL}$ of incubation media containing $20 \%$ fetal bovine serum, $1 \mu M$ insulin, and $100 \mathrm{n} M$ dexamethasone. Cells were incubated at $37^{\circ} \mathrm{C}$ in $95 \%$ air: $5 \% \mathrm{CO}_{2}$. After $4 \mathrm{~h}$, the medium was replaced with one containing $10 \%$ fetal bovine serum, $100 \mathrm{nM}$ insulin, $100 \mathrm{IU} / \mathrm{mL}$ of penicillin, $100 \mu \mathrm{g} / \mathrm{mL}$ of streptomycin, $250 \mathrm{ng} / \mathrm{mL}$ of amphotericin, and $2.5 \mathrm{mM}$ propionic acid. The medium was changed again at $16 \mathrm{~h}$ after seeding and was the same as the previous media, except that insulin was reduced to $10 \mathrm{n} M$ and carnitine was added to a final concentration of $1 \mathrm{~m} M$. Additionally, the following treatments were applied at $16 \mathrm{~h}$ after seeding: $1.0 \mathrm{mM}$ palmitic acid including $0.04 \mu \mathrm{Ci}$ [1${ }^{14} \mathrm{C}$ ]palmitic acid plus either 0.1 or $1.0 \mathrm{mM}$ of cis-9, cis12 linoleic acid (LA) or CLA (cis-9, trans-11 or trans10, cis-12). All fatty acids were bound to BSA in a 4:1 molar ratio. Nine dishes were used for each treatment within an animal. One set of triplicate dishes was used to measure metabolism of $\left[1-{ }^{14} \mathrm{C}\right]$ palmitic acid, another set was used to measure cellular TAG and media BHBA concentrations, and the last set of triplicate dishes was used to measure gluconeogenesis. In the latter set, medium was changed at $45 \mathrm{~h}$ after initiation of treatments. The fresh medium contained $2.5 \mathrm{~m} M$ propionic acid, including $0.06 \mu \mathrm{Ci}\left[2-{ }^{14} \mathrm{C}\right]$ propionic acid per flask to measure its metabolism to media glucose and cellular glycogen in the presence of the fatty acid treatments. All incubations were ended at $48 \mathrm{~h}$ after initial treatments were applied.

\section{Measurements and Analysis}

After the end of treatment, the medium was removed and stored at $-20^{\circ} \mathrm{C}$. Aliquots of medium were used to determine $\left[1-{ }^{14} \mathrm{C}\right]$ palmitic acid metabolism to acidsoluble products (ASP) and $\left[{ }^{14} \mathrm{C}\right]$ media TAG (Mashek et al., 2002). In a set of triplicate dishes not exposed to radiosotopes, media were analyzed for BHBA (Mashek and Beede, 2001). Cells were washed twice with Krebs buffer and then frozen with $1 \mathrm{~mL}$ of a dissociation buffer (Donkin and Armentano, 1993). In the dishes exposed to $\left[1-{ }^{14} \mathrm{C}\right]$ palmitic acid and those used for measurements of total cellular TAG, cells were thawed, scraped from dishes, and extracted (Folch et al., 1957). Extracts were spotted on TLC plates for separation of lipid classes and total cellular TAG, and $\left[1-{ }^{14} \mathrm{C}\right]$ palmitic acid metabolism to cellular lipids and media TAG were quantified (Mashek et al., 2002).

In the set of triplicate dishes containing $\left[2-{ }^{14} \mathrm{C}\right]$ propionic acid, media were removed and the dishes were washed twice with $1 \mathrm{~mL}$ of Krebs buffer, which was added to the original medium. The medium was frozen for later analysis of $\left[{ }^{14} \mathrm{C}\right]$ glucose (Mills et al., 1981). Concentrations of DNA (LaBarca and Paigen, 1980) and $\left[{ }^{14} \mathrm{C}\right]$ glycogen (Hue et al., 1975) were determined.

\section{Statistical Analysis}

Data were analyzed using the MIXED procedure of SAS (SAS Inst., Inc., Cary, NC). The model included fixed effects of treatment and fatty acid concentration, treatment $\times$ fatty acid concentration interaction, random effect of calf, and residual error term. Contrasts were used to test for differences between LA vs. the two CLA isomers and cis-9, trans-11 CLA vs. trans10, cis-12 CLA. For all comparisons, significance was declared at $P<0.05$.

\section{RESULTS AND DISCUSSION}

Monolayer cultures are used in our laboratory to test the effects of changing a controlled environment (i.e., media composition) on hepatic metabolism. Hepato- 
Table 1. Least squares means for $\left[1-{ }^{14} \mathrm{C}\right]$ palmitic acid metabolism to acid-soluble products, cellular lipids, and media triacylglycerol.

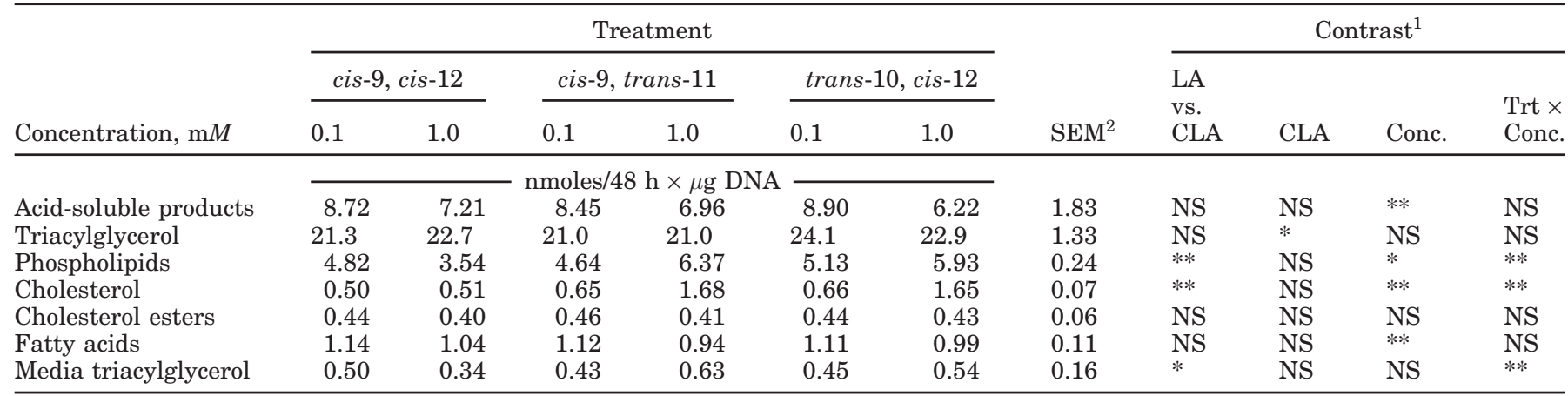

$* P<0.05$.

$* * P<0.001$.

${ }^{1}$ LA vs. CLA: $c i s-9$, cis- 12 linoleic acid vs. $c i s-9$, trans- $11+$ trans-10, cis- 12 conjugated linoleic acid; CLA = cis-9, trans-11 vs. trans-10, cis-12 conjugated linoleic acid; Conc. $=0.1$ vs. $1.0 \mathrm{~m} M$ of treatment fatty acids; Trt $\times$ conc. $=$ treatment fatty acid $\times$ concentration interaction.

${ }^{2} \mathrm{SEM}$ is derived from the interaction term. Data represent 9 replicates.

cytes in monolayer culture do not represent the physiological state of the donor animal. In support, previous research has shown that hepatocytes obtained from preruminating and ruminating calves have similar rates of gluconeogeneis (Donkin and Armentano, 1995). Indeed, cultured hepatocytes allow us to study factors affecting metabolism without the multitude of confounding factors that occur when treatments are applied to the whole animal. Hepatocytes have not been successfully cultured from tissue obtained from mature cows. Thus, hepatocytes from young calves provide a practical model for studying bovine hepatic metabolism.

Loor et al. (2002) showed that feeding soybean oil at $3.5 \%$ of the diet DM to lactating dairy cows increased concentrations of CLA and LA in several plasma lipid classes. In the plasma NEFA fraction, LA and cis-9, trans-11 CLA increased from approximately $4 \mu M$ and undetectable levels in the control diet to $6 \mu M$ and 2.3 $\mu M$ in cows fed soybean oil. In the current study, LA and CLA isomers were at concentrations of 100 or 1000 $\mu M$ in the media. Therefore, these values represent supraphysiological concentrations based on published data regarding plasma NEFA concentrations of LA and CLA.

\section{Oxidation}

Effects of CLA and the concentration of fatty acids on palmitic acid oxidation to ASP are shown in Table 1. Type of fatty acid had no effect on metabolism of palmitic acid to ASP. Increasing the concentration of fatty acids from 0.1 to $1.0 \mathrm{~m} M$ decreased metabolism of palmitic acid to ASP regardless of treatment. Media BHBA concentrations were increased from 4.75 to 6.03 $\mu \mathrm{g} / \mu \mathrm{g}$ of DNA $(P<0.0001)$ when the concentration of fatty acids increased from 0.1 to $1.0 \mathrm{~m} M$, but there were no differences due to type of fatty acid.

The effects of CLA on hepatic fatty acid oxidation in rodents are not clear. Feeding a mix of CLA isomers for $14 \mathrm{~d}$ increased ketone body production in rat livers (Sakono et al., 1999, 2002). Rodents fed CLA showed increased rates of mitochondrial and peroxisomal oxidation along with increased mRNA levels of enzymes involved in fatty acid catabolism (Takahashi et al., 2003). In contrast, several studies have shown that CLA may increase fatty acid oxidation via peroxisomes rather than mitochondria. Feeding CLA to rodents increased acyl-CoA oxidase (Belury et al, 1997; MoyaCamarena et al., 1999), the rate-limiting enzyme in peroxisomal oxidation, and stimulated peroxisome proliferation (Moya-Camarena et al., 1999). In contrast, CLA had no effect on hepatic carnitine palmitoyltransferase I, the rate-limiting enzyme in mitochondrial oxidation (Park et al., 1997; Clouet et al., 2001) and were poor substrates for mitochondrial oxidation compared with palmitoleic and LA acids (Demizieux et al., 2002). Based on the results of the present study, CLA at 0.1 or $1.0 \mathrm{~m} M$ does not appear to influence incomplete fatty acid oxidation to ketone bodies in bovine liver.

\section{Cellular and Media Lipids}

Effects of CLA on palmitic acid metabolism to cellular lipids and media TAG are shown in Table 1. Metabolism of palmitic acid to cellular TAG was increased for the treatment containing trans-10, cis-12 compared with cis-9, trans-11 CLA, but there were no differences between LA and CLA. As seen in Figure 1, total cellular TAG content increased for treatments containing CLA compared with LA (17.2 vs. $15.5 \mu \mathrm{g}$ of TAG/ $\mu \mathrm{g}$ of DNA; 


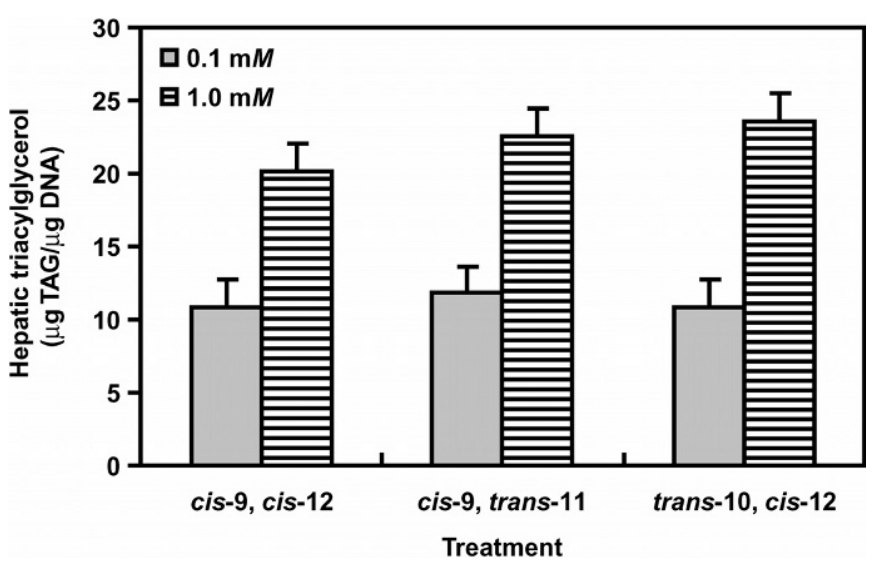

Figure 1. Effects of conjugated linoleic acid on hepatic triacylglycerol (TAG) concentrations. Linoleic acid (cis-9, cis-12) significantly decreased $(P<0.05)$ hepatic TAG concentrations compared with the conjugated linoleic acid isomers (cis-9, trans-11 and trans-10, cis-12). Data represent 9 replicates.

$P<0.05$ ), and when fatty acids were at $1.0 \mathrm{~m} M$ compared with $0.1 \mathrm{mM}(22.2 \mathrm{vs} .11 .2 \mu \mathrm{g}$ of TAG/ $\mu \mathrm{g}$ of DNA; $P<0.01)$. Metabolism of palmitic acid to media TAG was lower for LA compared with CLA $(P<0.01)$, but there was a treatment $\times$ concentration interaction $(P<$ 0.01). Palmitic acid metabolism to media TAG increased when the concentration of LA increased from 0.1 to 1.0 $\mathrm{m} M$, but decreased when the CLA isomers increased from 0.1 to $1.0 \mathrm{mM}$. Based on this interaction, it appears that the effects of CLA on increasing palmitic acid metabolism to media TAG reflect changes when CLA is at $1 \mathrm{~m} M$. In contrast, others have shown that trans-10, cis-12 CLA decreased hepatic TAG secretion in HepG2 cells (Yotsumoto et al., 1999; Lin et al., 2001). It should be noted that the $\left[{ }^{14} \mathrm{C}\right] \mathrm{TAG}$ in media was approximately 2 to $2.5 \%$ of intracellular $\left[{ }^{14} \mathrm{C}\right] \mathrm{TAG}$. Therefore, changes observed in media $\left[{ }^{14} \mathrm{C}\right] \mathrm{TAG}$, an indicator of $\left[{ }^{14} \mathrm{C}\right] \mathrm{TAG}$ export from hepatocytes, may be highly significant but are likely to have a negligible influence on cellular $\left[{ }^{14} \mathrm{C}\right] \mathrm{TAG}$ content.

Feeding a mixture of cis-9, trans-11 and trans-10, cis12 CLA isomers to mice increased hepatic TAG content compared with control groups fed either corn or sunflower oil (Belury et al., 1997; Clement et al., 2002). Similarly, exposing HepG2 cells to a mixture of cis-9, trans-11 and trans-10, cis-12 CLA isomers increased cellular TAG formation compared with a LA control (Jin Jun et al., 2000; Igarashi and Miyazawa, 2001). Of the CLA isomers, trans- 10 , cis- 12 increased $\left[{ }^{3} \mathrm{H}\right]$ glycerol incorporation into cellular TAG compared with cis-9, trans-11 CLA or LA in HepG2 cells (Lin et al., 2001). These data support the findings of increased cellular TAG content for hepatocytes exposed to CLA in the current study. However, all of the above mentioned in vitro studies used CLA or LA as the sole fatty acid in the media. Therefore, these studies do not consider the effects of CLA on metabolism of other fatty acids as does the current study.

A fatty acid $\times$ concentration interaction $(P<0.0001)$ was observed for metabolism of palmitic acid to cellular phospholipids and cholesterol. There were no differences between fatty acids at $0.1 \mathrm{~m} M$, but the CLA isomers increased and LA decreased palmitic acid metabolism to phospholipids and cholesterol at $1.0 \mathrm{mM}$.

The increase in palmitic acid metabolism to phospholipids and cholesterol may be explained by changes in the site of fatty acid oxidation. Both cis-9, trans-11 and trans-10, cis-12 CLA isomers are ligands for peroxisome proliferator-activated receptor- $\alpha$ (Moya-Camarena et al., 1999), and thus increase peroxisomal oxidative capacity (Belury et al., 1997). Additionally, it has been shown that acetyl-CoA generated from peroxisomal oxidation is preferentially incorporated into cholesterol (Hayashi and Miwa, 1989) and phospholipid (Hayashi and Takahata, 1991). Therefore, CLA may have increased peroxisomal oxidation of palmitic acid resulting in increased radiolabel incorporation into cholesterol and phospholipids.

In HepG2 cells, CLA does not affect phospholipid content (Jun et al., 2000; Igarashi and Miyazawa, 2001; Lin et al., 2001). Using the same model, a mixture of CLA isomers increased cholesterol concentrations (Igarashi and Miyazawa, 2001), whereas trans-10, cis12, but not cis-9, trans-11 CLA, decreased cholesterol concentrations (Lin et al., 2001). Although a direct comparison of peroxisomal oxidation between human and ruminant hepatocytes has not been done, an indirect comparison suggests that peroxisomal oxidation is far more prevalent in bovine hepatocytes (Veerkamp and van Moerkerk, 1986; Grum et al., 1994). These differences may in part explain the discrepancies in phospholipid and cholesterol metabolism between the current study and those utilizing HepG2 cells.

\section{Gluconeogenesis}

The type of fatty acid did not affect propionic acid metabolism to media glucose, cellular glycogen, or a combination thereof, but increasing the concentration of fatty acids from 0.1 to $1.0 \mathrm{~m} M$ decreased the formation of both gluconeogenic products (Table 2). The effects of CLA on gluconeogenesis have not been extensively studied. Exposure to CLA decreased gluconeogenesis in rat hepatocyte cultures at concentrations above $35 \mu M$, but had no effect at lower concentrations (Cantwell et al., 1999). Abomasal infusion of $14 \mathrm{~g}$ of trans-10, cis-12 CLA per day for $5 \mathrm{~d}$ had no effect on basal plasma glucose concentrations or glucose re- 
Table 2. Least squares means for the metabolism of $2.5 \mathrm{mM}\left[2-{ }^{14} \mathrm{C}\right]$ propionic acid to media glucose, cellular glycogen, and total gluconeogenic products (glucose + glycogen) from 45 to $48 \mathrm{~h}$ after treatments were applied.

\begin{tabular}{|c|c|c|c|c|c|c|c|c|c|c|c|}
\hline \multirow[b]{3}{*}{ Concentration, $\mathrm{m} M$} & \multicolumn{6}{|c|}{ Treatment } & \multirow[b]{3}{*}{$\mathrm{SEM}^{2}$} & \multirow{2}{*}{\multicolumn{4}{|c|}{ Contrast $^{1}$}} \\
\hline & \multicolumn{2}{|c|}{ cis -9, cis -12} & \multicolumn{2}{|c|}{$c i s-9$, trans-11 } & \multicolumn{2}{|c|}{ trans -10, cis -12} & & & & & \\
\hline & 0.1 & 1.0 & 0.1 & 1.0 & 0.1 & 1.0 & & $\begin{array}{l}\text { LA vs. } \\
\text { CLA }\end{array}$ & CLA & Conc. & $\begin{array}{l}\text { Trt } \times \\
\text { Conc. }\end{array}$ \\
\hline & & & amoles & $\mathrm{h} \times \mu \mathrm{g}$ & DNA - & & & & & & \\
\hline \multirow{3}{*}{$\begin{array}{l}\text { Media glucose } \\
\text { Cellular glycogen } \\
\text { Total gluconeogenic } \\
\text { products }\end{array}$} & 2.41 & 2.27 & 2.34 & 2.31 & 2.57 & 2.24 & 0.22 & NS & NS & $* *$ & NS \\
\hline & 1.35 & 1.26 & 1.31 & 1.22 & 1.30 & 1.29 & 0.09 & NS & NS & $*$ & NS \\
\hline & 3.83 & 3.46 & 3.65 & 3.53 & 3.87 & 3.54 & 0.27 & NS & NS & $*$ & NS \\
\hline
\end{tabular}

$* P<0.05, * * P<0.10$

${ }^{1}$ LA vs. CLA: $c i s-9$, cis-12 linoleic acid vs. cis-9, trans- $11+$ trans-10, cis-12 conjugated linoleic acid; CLA = cis-9, trans-11 vs. trans-10, cis-12 conjugated linoleic acid; Conc. $=0.1$ vs. $1.0 \mathrm{~m} M$ of treatment fatty acids; Trt $\times$ conc. $=$ treatment fatty acid $\times$ concentration interaction

${ }^{2} \mathrm{SEM}$ is derived form the interaction term. Data represent 9 replicates.

sponse to insulin challenge in lactating dairy cows (Baumgard et al., 2002). Feeding $0.4 \%$ of the diet as trans-10, cis-12 CLA decreased phosphoenolpyruvate carboxykinase mRNA in rodents, which may be explained by a 10 -fold increase in plasma insulin concentrations compared with cis-9, trans-11 CLA or LA treatments (Clement et al., 2002). Based on the limited literature, it appears that CLA has no effect on gluconeogenesis.

\section{CONCLUSIONS}

Overall, exposure of monolayer cultures of bovine hepatocytes obtained from 7- to 10-d-old calves to supraphysiological concentrations of CLA isomers elicited subtle changes in lipid metabolism and no changes in gluconeogenesis. The most pronounced effects of CLA were on phospholipid and cholesterol metabolism when CLA concentrations were at $1 \mathrm{~m} M$. Therefore, it appears that very high concentrations of CLA are needed to invoke changes in hepatic lipid metabolism. If results from this study reflect effects of CLA in vivo, physiological concentrations of CLA in plasma would not likely affect hepatic lipid or glucose metabolism.

\section{ACKNOWLEDGMENTS}

The authors express their appreciation to S. Donkin for helpful discussion on monolayer cultures and to $\mathrm{S}$. Bertics and K. Lundberg for their technical assistance.

\section{REFERENCES}

Bauman, D. E., and J. M. Griinari. 2001. Regulation and nutritional manipulation of milk fat: Low-fat milk syndrome. Livest. Prod. Sci. 70:15-29.

Baumgard, L. H., B. A. Corl, D. A. Dwyer, and D. E. Bauman. 2002. Effects of conjugated linoleic acids (CLA) on tissue response to homeostatic signals and plasma variables associated with lipid metabolism in lactating dairy cows. J. Anim. Sci. 80:1285-1293.

Belury, M. A., S. Y. Moya-Camarena, K. L. Liu, and J. P. Vanden Heuvel. 1997. Dietary conjugated linoleic acid induces peoxisomespecific enzyme accumulation and ornithine decarboxylase activity in mouse liver. J. Nutr. Biochem. 8:579-584.

Cantwell, H., R. Devery, M. Oshea, and C. Stanton. 1999. The effect of conjugated linoleic acid on the antioxidant enzyme defense system in rat hepatocytes. Lipids 34:833-839.

Clement, L., H. Poirier, I. Niot, V. Bocher, M. Guerre-Millo, S. Krief, B. Staels, and P. Besnard. 2002. Dietary trans-10, cis-12 conjugated linoleic acid induces hyperinsulinemia and fatty liver in the mouse. J. Lipid Res. 43:1400-1409.

Clouet, P., L. Demizieux, J. Gresti, and P. Degrace. 2001. Mitochondrial respiration on rumenic and linoleic acids. Biochem. Soc. Trans. 29:320-325.

Demizieux, L., P. Degrace, J. Gresti, O. Loreau, J. P. Noel, J. M. Chardigny, J. L. Sebedio, and P. Clouet. 2002. Conjugated linoleic acid isomers in mitochondria: Evidence for an alteration of fatty acid oxidation. J. Lipid Res. 43:2112-2122.

Donkin, S. S., and L. E. Armentano. 1993. Preparation of extended in vitro cultures of bovine hepatocytes that are hormonally responsive. J. Dairy Sci. 71:2218-2227.

Donkin, S. S., and L. E. Armentano. 1995. Insulin and glucagons regulation of gluconeogenesis in preruminating and ruminating bovine. J. Anim. Sci. 73:546-551.

Folch, J., M. Lees, and G. H. Sloane Stanley. 1957. A simple method for the isolation and purification of total lipids from animal tissues. J. Biol. Chem. 226:497-509.

Griinari, J. M., B. A. Corl, S. H. Lacy, P. Y. Chouinard, K. V. V. Nurmela, and D. E. Bauman. 2000. Conjugated linoleic acid is synthesized endogenously in lactating dairy cows by $\Delta^{9}$-desaturase. J. Nutr. 130:2285-2291.

Grum, D. E., L. R. Hansen, and J. K. Drackley. 1994. Peroxisomal $\beta$-oxidation of fatty acids in bovine and rat liver. Comp. Biochem. Physiol. 109B:281-292.

Hayashi, H., and A. Miwa. 1989. The role of peroxisomal fatty acyl$\mathrm{CoA} \beta$-oxidation in bile acid biosynthesis. Arch. Biochem. Biophys. 274:582-589.

Hayashi, H., and S. Takahata. 1991. Role of peroxisomal fatty acylCoA $\beta$-oxidation in phospholipid biosynthesis. Arch. Biochem. Biophys. 284:326-331.

Hue, L., F. Bontemps, and H. G. Hers. 1975. The effect of glucose and of potassium ions on the interconversion of the two forms of glycogen phosphorylase and glycogen synthetase in isolated rat liver preparations. Biochem. J. 152:105-114.

Igarashi, M., and T. Miyazawa. 2001. The growth inhibitory effect of conjugated linoleic acid on a human hepatoma cell line, HepG2, is induced by a change in fatty acid metabolism, but not the 
facilitation of lipid peroxidation in the cells. Biochim. Biophys. Acta 1530:162-171.

Jun, W., H. C. Yang, and B. H. S. Cho. 2000. Comparison of conjugated linoleic acid and linoleic acid acid on cytotoxicity, synthesis, and secretion of lipids in HepG2 cells. In Vitro Mol. Toxicol. 13:181-189.

LaBarca, C., and K. Paigen. 1980. A simple, rapid, and sensitive DNA assay procedure. Anal. Biochem. 102:344-352.

Lin, Y., E. Schuurbiers, S. Van der Veen, and E. A. M. De Deckere. 2001. Conjugated linoleic acid isomers have differential effects on triglyceride secretion in HepG2 cells. Biochim. Biophys. Acta 1533:38-46.

Loor, J. J, L. E. Quinlan, A. B. P. A. Bandara, and J. H. Herbein. 2002. Distribution of trans-vaccenic acid and cis-9, trans-11-conjugated linoleic acid (rumenic acid) in blood plasma lipid fractions and secretion in milk fat of Jersey cows fed canola or soybean oil. Anim. Res. 51:119-134.

Mashek, D. G., and D. K. Beede. 2001. Peripartum responses of dairy cows fed energy-dense diets for 3 or 6 weeks prepartum. J. Dairy Sci. 84:115-125.

Mashek, D. G, S. J. Bertics, and R. R. Grummer. 2002. Metabolic fate of long chain unsaturated fatty acids and their effects on palmitic acid metabolism and gluconeogenesis in bovine hepatocytes. J. Dairy Sci. 85:2283-2289.

Mills, S. E., L. E. Armentano, R. W. Russell, and J. W. Young. 1981. Rapid and specific isolation of radioactive glucose form biological samples. J. Dairy Sci. 64:1719-1723.

Moya-Camarena, S. Y., J. P. Vanden Heuvel, S. G. Blanchard, L. A. Leesnitzer, and M. A. Belury. 1999. Conjugated linoleic acid is a potent naturally occurring ligand and activator of PPAR $\alpha$. J. Lipid Res. 40:1426-1433.

Park, Y., K. J. Albright, W. Liu, J. M. Storkson, M. E. Cook, and M. W. Pariza. 1997. Effect of conjugated linoleic acid on body composition in mice. Lipids 32:853-858.
Piperova, L. S., J. Sampugna, B. B. Teter, K. F. Kalscheur, M. P. Yurawecz, Y. Ku, K. M. Morehouse, and R. A. Erdman. 2002. Duodenal and milk trans octadecenoic acid and conjugated linoleic acid (CLA) isomers indicate that postabsorptive synthesis is the predominant source of cis-9-containing CLA in lactating dairy cows. J. Nutr. 132:1235-1241.

Piperova, L. S., B. B. Teter, I. Bruckental, J. Sampugna, S. E. Mills, M. P. Yurawecz, J. Fritsche, K. Ku, and R. A. Erdman. 2000. Mammary lipogenic enzyme activity, trans fatty acids and conjugated linoleic acids are altered in lactating dairy cows fed a milk fat-depressing diet. J. Nutr. 130:2568-2574.

Rahman, S. M., M. N. Huda, M. N. Uddin, and S. Akhteruzzaman. 2002. Short-term administration of conjugated linoleic acid reduces liver triglyceride concentration and phosphatidate phosphohydrolase activity in OLETF rats. J. Biochem. Mol. Biol. 35:494-497.

Sakono, M., F. Miyanaga, S. Kawahara, K. Yamauchi, N. Fukuda, T. Iwata, and M. Sugano. 1999. Dietary conjugated linoleic acid reciprocally modifies ketogenesis and lipid secretion by the rat liver. Lipids 34:997-1000.

Sakono, M., K. Yuji, F. Miyanaga, S. Tamaru, M. Fujita, N. Fukuda, K. Tsutsumi, T. Iwata, M. Kasai, and M. Sugano. 2002. Combined effects of dietary conjugated linoleic acid and sesamin on triacylglycerol and ketone body production in rat liver. J. Nutr. Sci. Vitaminol (Tokyo). 48:405-409.

Stangl, G. I. 2000. Conjugated linoleic acid exhibit a strong fat-tolean partitioning effect, reduce serum VLDL lipids and redistribute tissue lipids in food-restricted rats. J. Nutr. 130:1140-1146.

Veerkamp, J. H., and H. T. B. Van Moerkerk. 1986. Peroxisomal fatty acid oxidation in rat and human tissues. Effects of nutritional state, clofibrate treatment, and postnatal development in the rat. Biochim. Biophys. Acta 85:301-310.

Yotsumoto, H., E. Hara, S. Naka, R. O. Adlof, E. A. Emken, T. Yanagita. 1999. 10trans, 12cis-linoleic acid reduces apolipoprotein B secretion in HepG2 cells. Food Res. Int. 31:403-409. 